\title{
Experimental study on the shape of plunge pool in the Horizontal Swirl Spillway Tunnel
}

\author{
Heng Zhou ${ }^{*}$, Hui $\mathrm{Li}^{2}$, Ruijiao Xing ${ }^{1}$, Xinlei Guo ${ }^{3}$, Haitao Wang ${ }^{1}$, Shengjie Di ${ }^{1}$ \\ ${ }^{1}$ Power China, Northwest Engineering Corporation Limited, 710065, Xi'an, Shaanxi, China \\ ${ }^{2}$ State Grid Gansu Electric Power Company, Lanzhou, 730070, China \\ ${ }^{3}$ China Institute of Water Resources and Hydropower Research, Beijing, 10038, China
}

\begin{abstract}
According to the study on the shape of plunge pool in the horizontal swirl spillway tunnel, the design scheme of a plunge pool with better energy dissipation effect is proposed. Based on the hydraulic physical model test, which includes atmospheric pressure and decompression tests, and combined with the different design scheme of a plunge pool, measurement results of fluctuating pressure. Main frequency and sidewall pressure are analysed. The results show that the inlet section of the plunge pool is connected by a gradual variable section which length of gradient segment $6 \mathrm{~m}$. The shape of the gradient section is a long round variable gate hole. To improve the side wall pressure, the inlet section is increasing from $6.0 \mathrm{~m}$ to $14.0 \mathrm{~m}$. Finally, the proposed plunge pool has the advantages of simple design and convenient construction, and these studies provide reference and support for the design of hydropower dams in western China.
\end{abstract}

\section{Introduction}

In the various structures of dam engineering, the plunge pool is one of the main engineering measures for flood discharge and energy dissipation of the dam (Figure 1). Whether the structural shape is optimised or not is an important factor affecting the safe operation of the dam[12]. At present, the research on the shape of a plunge pool is mainly carried out by hydraulic physical model test, theoretical calculation and numerical simulation[3-4]. These methods could improve the stability capability of the plunge pool by shape optimisation[5]. At present, the research on the shape of a plunge pool is very rich, but the research on the shape of a plunge pool around horizontal swirl spillway tunnel is relatively less. So this study uses hydraulic tests to carry out the comparative design of various shapes. Moreover, the energy dissipation of plunge pool under normal pressure and decompression test is analysed. These could provide support for similar horizontal swirl spillway tunnel plunge pool shape design of hydropower stations.

\section{Introduction of shape optimization test}

\subsection{Experiment purpose}

The plunge pool is the connection area between the swirling tunnel and the dewatering tunnel. It is not only an vital part of adjusting the flow pattern, but also an important part of water energy dissipation. The degree of flow turbulence, aeration concentration and fluctuating pressure in the pond are important factors affecting operation safety. Therefore, the study's goal on the shape of the plunge pool is to reduce the fluctuating pressure (the standard deviation of fluctuating pressure is not more than $50 \mathrm{kPa}$, and the minimum fluctuating pressure is not less than $-70 \mathrm{kPa}$ ). The outlet flow is stable. The structure has a good energy dissipation effect. What is more, it is simple and convenient for construction.

\subsection{Experimental scheme}

\subsubsection{Suggestions for experimental design}

According to the spatial position of the plunge pool, the study on the structural shape of the plunge pool is divided into two regions, namely, the connection part between the inlet of the plunge pool and the swirling tunnel (inlet) and the connection part between the outlet of the plunge pool and the return tunnel (outlet).

For the inlet area of the plunge pool, the cross-section of the swirling tunnel is circular, and the cross-section of the plunge pool section is gate-shaped. The gradient section is longer, set at the connection between the swirl tunnel section and the plunge pool section. The change of shape is slow, the gradient of the flow line is small, and the hydraulic conditions are good. If the reconstruction project is large, the water flow energy dissipation rate will decrease. The length of the gradient section becomes shorter and the hydraulic conditions become worse. In addition, the engineering quantity of reconstruction is small, and the energy dissipation rate of water flow will increase. Therefore, the length of the gradient section

\footnotetext{
* Corresponding author: 1728@nwh.cn
} 
should be as short as possible based on meeting the hydraulic conditions, structural safety and water flow energy dissipation requirements.

For the outlet area of the plunge pool, the contraction pier at the outlet of the plunge pool is used to form the plunge pool in the tunnel in the downstream section of the swirl tunnel. It is promoting energy dissipation of water flow in ponds to increase energy dissipation rate. And the strong turbulent flow in the pond is unfavourable to the lining structure. Moreover, the modification of the shape of this part will also cause a series of changes in the discharge capacity, pressure, flow velocity and energy dissipation effect of other parts. Therefore, various factors should be comprehensively considered when studying the structural shape of a plunge pool.

\subsubsection{Experimental model}

According to the design criterion of the plunge pool, three types of plunge pool are designed, and the specific design scheme is as follows:

The first kind (Figure 1 a): the connection between the inlet of the water cushion pool and the cyclone hole is suddenly expanded, and there is no transition slope section. The thickness of the outlet side pier and bottom triangular ridge are $2.2 \mathrm{~m}$

The second kind (Figure $1 \mathrm{~b}$ ): there should be some ramp connection around import, which length is $6 \mathrm{~m}$. The exit side wall and the triangle vertex of the middle pier are on the same section and the downstream slope is slowed down.

The third kind (Figure $1 \mathrm{c}$ ): the import structure is same as the second kind. There is triangle continuous bucket in the downstream exit end, which height is $2.5 \mathrm{~m}$. And the shape of side wall is triangle bucket, which height is $2.3 \mathrm{~m}$.
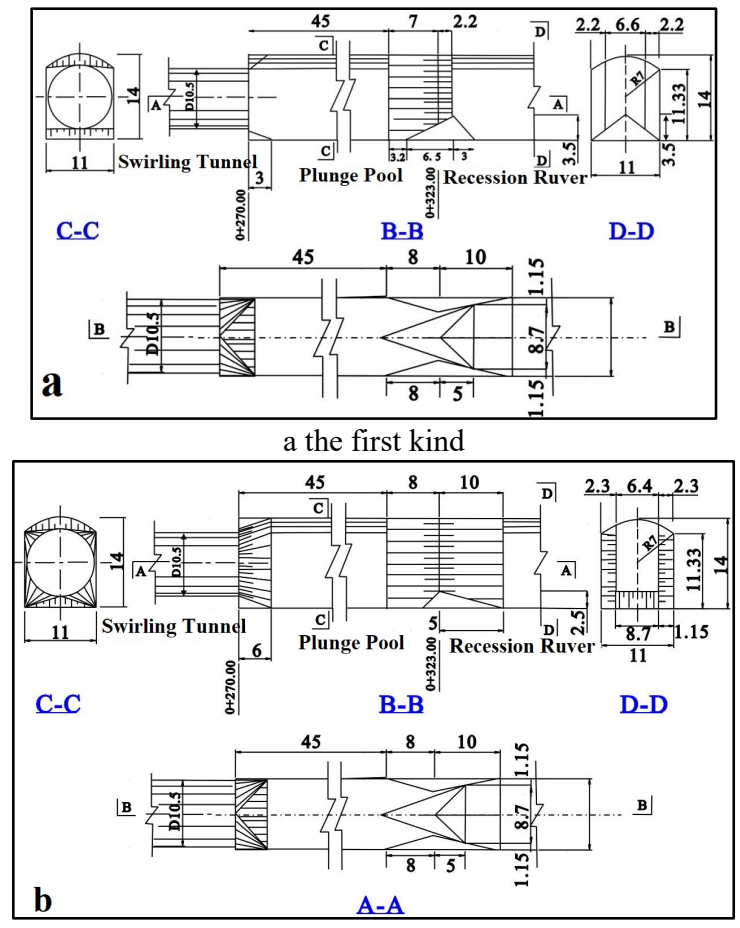

$\mathrm{b}$ the second kind

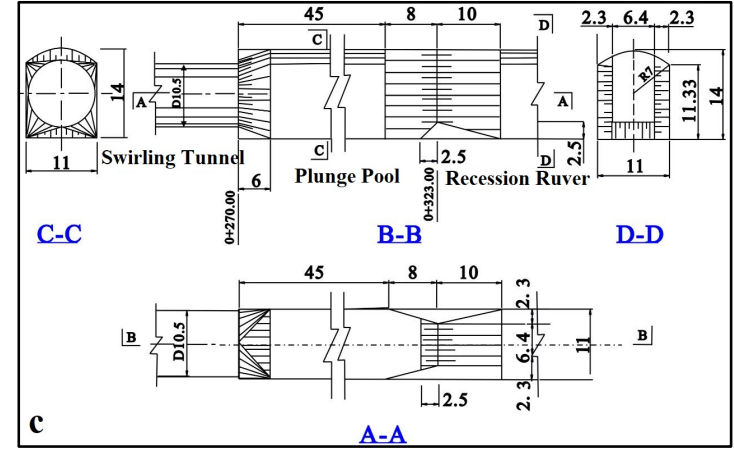

c the third kind

Fig. 1. The picture shows that three types of plunge pool(Unit : meter).

\subsubsection{Experiment process}

The optimum design experiment of horizontal swirling tunnel plunge pool is divided into two stages. First, through the normal pressure hydraulic model test, the preliminary shape is determined in three kinds of design. Then further verification and optimization of structure by hydraulic model test.

\section{Results analysis}

\subsection{Analysis of normal pressure test}

Through the collation and analysis of the test data, the inlet water in scheme one suddenly expands(Table 1), the surrounding eddy current occurs, and the flow pulsation is large. There is no cavity pocket in the lower exit. The range of low fluctuating pressure is large. In addition, there are characteristics of small pulsating pressure, small low pressure and low main frequency in the second kind. But due to the complex construction of the second kind, this makes construction difficult. And the third kind is close to the first kind in the aspect of the fluctuating pressure. In addition, its structure is simple in shape and convenient in construction. At last, the third kind is advised to design the plunge pool in the study.

Table 1 The results of normal pressure test results

\begin{tabular}{|c|c|c|c|c|}
\hline \multicolumn{2}{|l|}{ Scheme } & $\begin{array}{l}\text { The } \\
\text { First } \\
\text { kind }\end{array}$ & $\begin{array}{l}\text { The } \\
\text { Second } \\
\text { kind }\end{array}$ & $\begin{array}{l}\text { The } \\
\text { Third } \\
\text { kind }\end{array}$ \\
\hline \multirow{2}{*}{$\begin{array}{l}\text { Standard deviation } \\
\text { of maximum } \\
\text { fluctuating pressure } \\
/ \mathrm{kP}_{\mathrm{a}}\end{array}$} & Import & 59.66 & 49.24 & 56.44 \\
\hline & Exit & 38.9 & $<40.0$ & 39.9 \\
\hline \multirow{2}{*}{$\begin{array}{l}\text { Minimum pulsating } \\
\text { pressure }\left(\mathrm{kP}_{\mathrm{a}}\right)\end{array}$} & Import & $<-70$ & -34.6 & $\begin{array}{l}- \\
29.28\end{array}$ \\
\hline & Exit & $<-70$ & $<-70$ & $<-70$ \\
\hline \multirow{2}{*}{$\begin{array}{l}\text { Maximum principal } \\
\text { frequency }\left(\mathrm{H}_{\mathrm{Z}}\right)\end{array}$} & plunge pool & 2.33 & 3.50 & 12.39 \\
\hline & $\begin{array}{l}\text { Dewatering } \\
\text { tunnel }\end{array}$ & 1.00 & 2.69 & 1.86 \\
\hline \multicolumn{2}{|c|}{$\begin{array}{l}\text { Number of points below }-70 \mathrm{kPa} \\
\text { pressure }\end{array}$} & 13 & 2 & 6 \\
\hline
\end{tabular}




\subsection{Analysis of normal pressure test}

A similar scale of the decompression hydraulic model developed in this study is $1: 40$. The inlet section of the plunge pool is connected by a transitional section. Its length is $6 \mathrm{~m}$, and its shape is transformed from a circle to a gate hole. There appears some phenomenon in the inlet section (i.e., separation of sidewall flow, large negative pressure at measuring points and evaporating pressure). The form of contraction section at the outlet of plunge pool is bottom and side triangular bucket. There is an obvious cavitation separation phenomenon in the outlet section. The cavitation characteristics of the exit section is weak. In addition, there are weak cavitation clouds in the retreating tunnel and its junction with the diversion tunnel. So it can be seen that the import, export and joint areas need further optimization design. This study takes the inlet section of plunge pool shape as the main research object to carry out the optimization design. The specific decompression test results are as follows:

First of all, the test and comparison of the average pressure of the inlet section under normal and decompression conditions are carried out. A total of 24 pressure measuring points on two cross-sections are arranged (Figure 2,3\&4). The time-averaged pressure values of each measuring point under design and check conditions are shown in table 2 . The pressure values of the first circle of the joint section is low. Measuring point pressure reaches or exceeds vaporization pressure at atmospheric pressure in this area. The minimum pressure for decompression is $-8.97 \times 9.8 \mathrm{kPa}$. In order to improve the sidewall pressure and anti-cavitation performance, the import section is extended from $6.0 \mathrm{~m}$ to $14.0 \mathrm{~m}$. Normal pressure test of modified scheme shows the side wall pressure of this part is positive (Figure $3 \& 4$ ). The pressure of 3 \# and 12 \# measuring points in decompression test is slightly lower than normal pressure. The pressure of 6 \# and 9 \# measuring points is slightly higher than normal pressure (Table 1). After modification, the flow is smoother, but it has a certain impact on the energy dissipation effect.

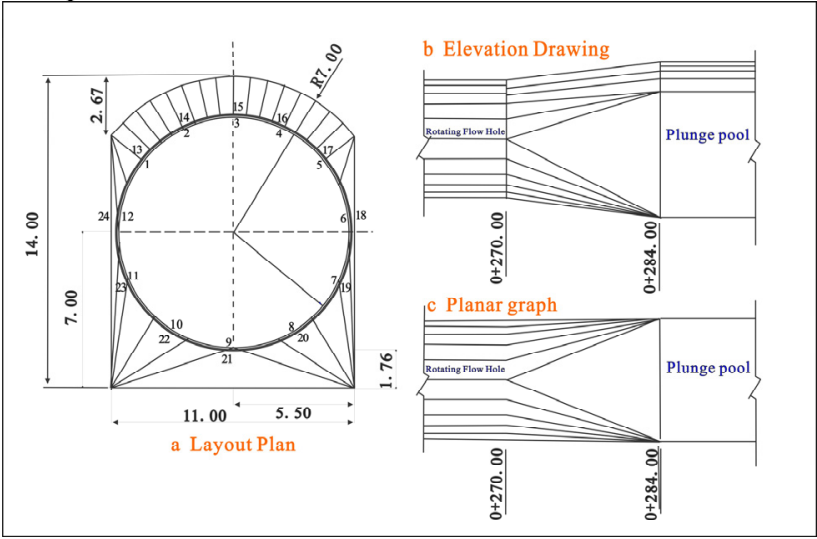

Fig. 2. The picture shows that modification diagram of connection section between swirling tunnel and water cushion pond and layout of pressure measuring points

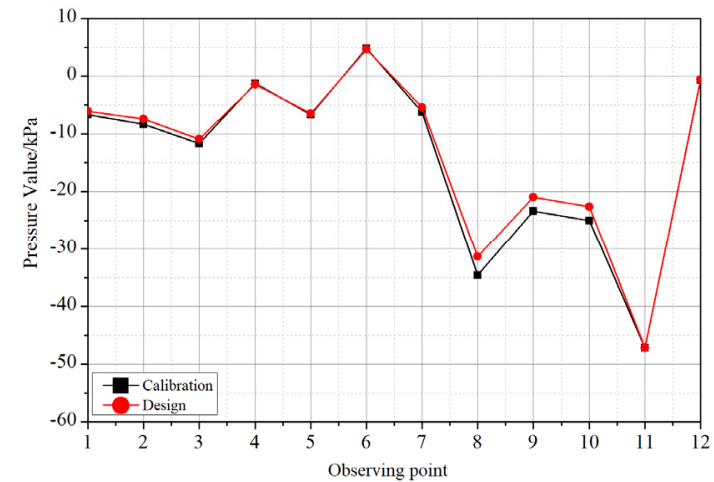

a Original Scheme-Normal (9.8kpa)

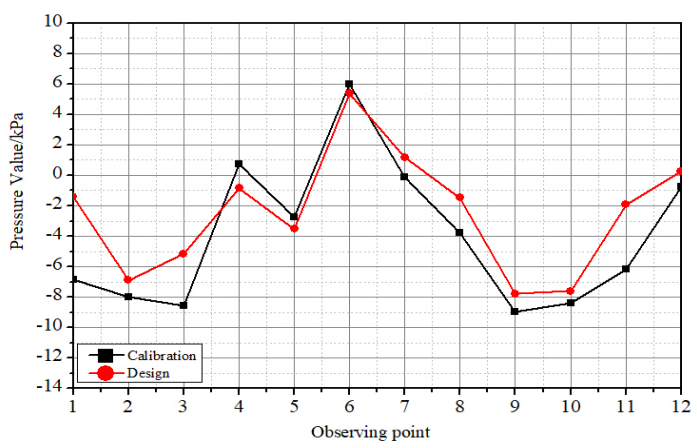

b Original Scheme-Decompression(9.8kpa)

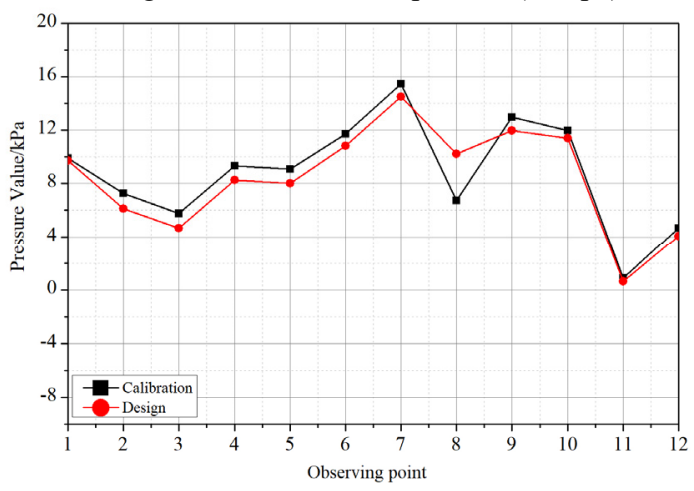

c Revised scheme -Normal(9.8kpa)

Fig. 3. The observation point is located at the junction of swirling tunnel and plunge pool ( first circle )

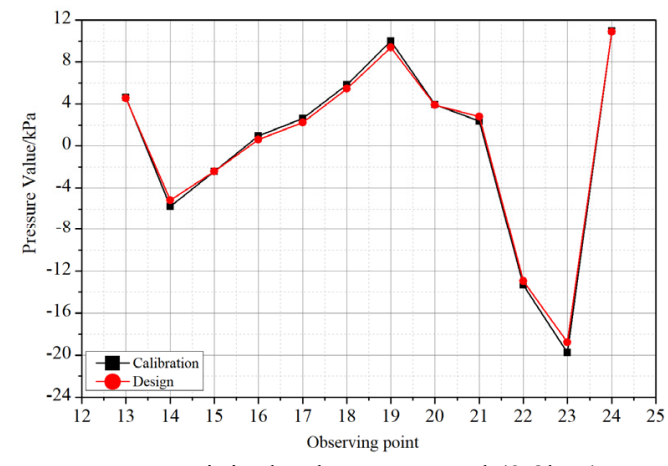

a Original Scheme-Normal (9.8kpa) 


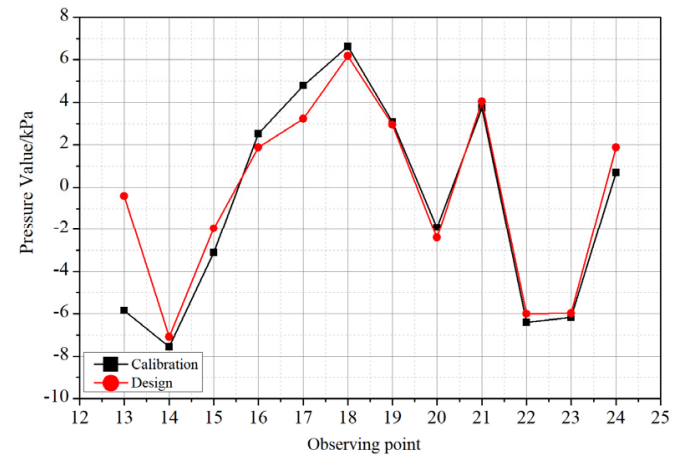

b Original Scheme-Decompression(9.8kpa)

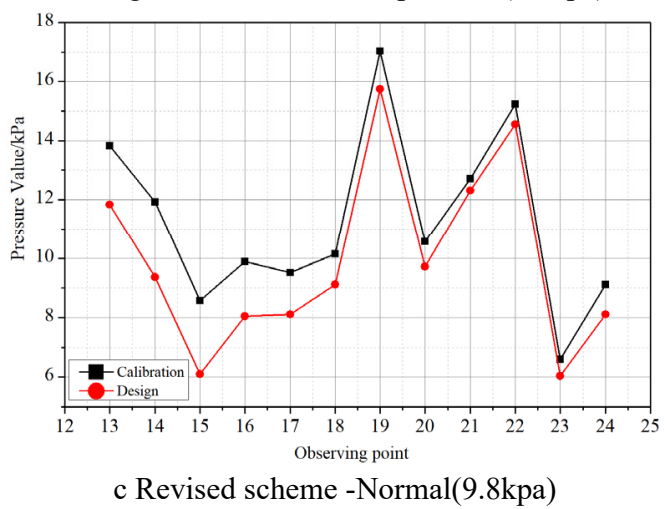

Fig. 4. The observation point is located at the junction of swirling tunnel and plunge pool (second circle )

\section{Conclusion}

In this paper, the hydraulic model test is used to carry out a variety of plunge pool design comparison, and the energy dissipation design method of plunge pool is proposed. The main results are as follows:

(1) The length of the gradient section should be as short as possible based on satisfying hydraulic conditions, structural safety and flow energy dissipation requirements.

(2) Through normal pressure test, the preliminary design of plunge pool as follows: there should be some ramp connection around import, which length is $6 \mathrm{~m}$. the import structure is the same as the second kind. There is a triangle continuous bucket in the downstream exit end, which height is $2.5 \mathrm{~m}$. Moreover, the shape of the side wall is triangle bucket, which height is $2.3 \mathrm{~m}$.

(3) The inlet section of a plunge pool was taken as the main research object, and the inlet section was lengthened from $6.0 \mathrm{~m}$ to $14.0 \mathrm{~m}$. The atmospheric pressure test of the modified scheme shows that the flow is smoother after modification, but it has a certain impact on energy dissipation.

\section{Acknowledgments}

This work was financially supported by the major science and technology project of Northwest Engineering Corporation Limited, Power China. In the meantime, we express thanks to our colleagues for their help and technical support.

\section{References}

1. HE, L.Q. (2006) Experiment and optimize run the level spiraling flow spillway tunnel Gongboxia. $\mathrm{Xi}$ 'an University of Technology.

2. DONG, X.L, GAO, J.Z. (1993) Review on appilication of vertical shaft tunnel rebuilt by diversion tunnel. Water Power, 2: 47-50 .

3. YANG K.L., HAN K., WANG T. (2009) Model similarity laws of gas-liquid mixed flow in horizontal swirling flow tunnels with vertical shaft. Journal of Hydraulic Engineering, 40 (12): 1416-1424.

4. NAN J.H., NIU Z.M., ZHANG D. (2016) Study on velocity characteristics of cavity gyrating flow in gyrating discharge tunnel. Journal of Si-chuan University ( Engineering Science Edition), 48( 2) : 41-47.

5. JU, J, WEI, Y, CHEN, N.S, (2004) Experiment study of horizontal vortex spillway tunnel in Gongboxia hydroelectric project $[\mathrm{J}]$. Journal of Hydroelectric Engineering, 23(5): 88-91. 